Eur J Clin Chem Clin Biochem

$1995 ; 33: 813-823$

(c) 1995 Walter de Gruyter \& Co. Berlin - New York

\title{
The MTT Tetrazolium Salt Assay Scrutinized: How to Use this Assay Reliably to Measure Metabolic Activity of Cell Cultures in vitro for the Assessment of Growth Characteristics, $\mathrm{IC}_{50}$-Values and Cell Survival
}

\author{
By Anieta M. Sieuwerts, Jan G. M. Klijn, Harry A. Peters and John A. Foekens \\ Division of Endocrine Oncology (Department of Medical Oncology), Dr. Daniel den Hoed Cancer Center, \\ Rotterdam, The Netherlands
}

(Received April 24/July18, 1995)

Summary: The 3-(4,5-dimethylthiazol-2-yl)-2,5-diphenyltetrazoliumbromide (MTT) assay is widely used for in vitro measurement of the metabolic viability of cell cultures subjected to different culture conditions. This convenient assay, which is based on the ability of viable cells to produce formazan, can be affected significantly by a number of conditions. These conditions can be roughly divided into two groups, firstly influences which affect the spectrum of the produced formazan and secondly influences which affect the amount of formazan produced per cell. We studied the various chemical and biochemical aspects involved in the MTT assay. Our data indicate that microscopical viewing of cell cultures before and after performing the assay, a medium renewal with a well-defined MTT-incubation medium at the end of the culture period and regular cell counting are essential steps to ensure a reliable performance of the MTT assay. In conclusion, providing the necessary precautions are taken, the MTT assay can be used reliably to measure metabolic activity of cell cultures in vitro for the assessment of growth characteristics, $\mathrm{IC}_{50}$-values and cell survival.

\section{Introduction}

Viable cells are able to reduce the water-soluble yellow coloured MTT to a water-insoluble purple coloured formazan product. The amount of coloured formazan product formed, determined spectrophotometrically after dissolving the formazan crystals in dimethyl sulphoxide, is proportional to the metabolic activity and the number of cells in the test sample. The general idea is that this metabolic activity requires functional mitochondria $(1-5)$. However, recently it has been shown that cells with "poisoned" mitochondria are able to produce the same amount of formazan when compared to cells with normal mitochondria (6).

The assay was first described for use in microtitre plates as a rapid colorimetric assay for cellular growth and survival (3), and in various studies the performance of this assay has been compared with other available assays.
When the purpose of a particular assay is to replace or validate another assay, one has to understand the basic principles of the assays studied before any comparison can be made. In contrast to the MTT assay and the labelled precursors incorporation assay (5-7), the adenosine triphosphate assay (8), the glucose utilization assay (9), the carbon monoxide production assay and the chemiluminescent assay (10), most other assays do not distinguish between metabolically active and inactive cells. Notwithstanding, the MTT assay has also been compared with assays

a) which test membrane integrity, like the dye exclusion assay (1), and the $\left[{ }^{3} \mathrm{H}\right]$ thymidine-, ${ }^{51} \mathrm{Cr}$ - and lactate dehydrogenase-release assays (11), with assays

b) which are a measure of the total amount of whole cells present either by direct cell counting $(2,7,12)$ or by measurement of the total amount of protein present 
after staining with neutral red $(10)$ or sulphorhodamine $B(13,14)$ or by measurement of the total amount of cell nuclei present after staining with crystal violet (15) or Hoechst 33258 or 33342 (5) and with

c) the clonogenic assay which assesses the reproductive capacity of single cells $(1,4,12,13)$.

Taking these differences between assays into account, the general conclusion was that the MTT assay may be used interchangeably with other assays.

The MTT assay has been utilized with fresh human tumour cells and established cell lines of different origins, i. e. for the assessment of hormone and growth factorstimulated growth $(5,16)$, for assessment of both cytostatic and cytotoxic effects (5), for chemosensivity testing of fresh human tumour cells (17) and established cell lines $(1,10,12,18)$ of different origins, for measuring radiosensitivity (4), for measuring clonogenicity (13), for quantitating growth factors in fluids (15), for detecting microbial activity (19) and for use in three-dimensional histocultures (20).

In addition to the overall satisfactory results obtained with the MTT assay, possible pitfalls and recommendations for optimization of the assay have been described. These pitfalls include spectrum shifts of formazan/dimethyl sulphoxide solutions, accompanied by decreases in absorbance values $(1,12,15)$, the necessity to establish assay conditions concerning time of exposure to test agents as well as optimal MTT concentration and incubation time for each individual cell line, the inability of some cells to produce the MTT formazan precipitate (18) and underestimation of the inhibitory effect of interferons (2), mitomycin (7) and methotrexate (21).

In the present study we have addressed some of the described problems and additional technical problems concerning the use of the MTT assay. Furthermore, acknowledging the fact that the MTT assay is primarily a cell viability assay, we offer solutions to overcome these problems and finally show how the MTT assay can be used for obtaining results concerning survival, $\mathrm{IC}_{50}$-values and growth characteristics of different cell cultures which in our view qualify as reliable.

\section{Materials and Methods}

Materials

\section{Chemicals}

Powdered culture media were obtained from Sigma (St. Louis, $\mathrm{MO}, \mathrm{USA}$ ). $\mathrm{NaHCO}_{3}$ from Merck (Darmstadt, Germany), penicillin/streptomycin from Northumbria Biologicals (Cramlington, UK). L-glutamine, trypsin-EDTA and gentamicin from Life Technologies (Breda, The Netherlands), trypsin inhibitor from Sigma, iron-supplemented bovine calf serum from HyClone (Logan, UT, USA), purified bovine serum albumin from Behringwerke (Mar- burg, Germany), porcine insulin from Organon (Oss, The Netherlands), 17 $\beta$-oestradiol from Merck and epidermal growth factor was purchased from BTI (Stoughton, MA, USA). 3-(4,5-Dimethylthiazol-2-yl)-2,5-diphenyltetrazoliumbromide (MTT) and trypan blue were obtained from Sigma and dimethyl sulphoxide (Uvasol and "pro analysi" quality), $\mathrm{NaOH}, \mathrm{NH}_{3}$ and $\mathrm{HCl}$ from Merck.

\section{Cell-lines}

MCF-7, MDA-MB-231, T47-D and HT-29 cells were obtained from the American Type Culture Collection (Rockville, MD, USA). ZR/75.1 cells were a gift from Dr. R. J. B. King (ICRF, London, UK). ZR/HERc cells originated from ZR/75.1 cells after introduction of the human receptor for epidermal growth factor cDNA utilizing a retroviral factor (22). EVSA-T cells were a gift from Dr. N. DeVleeschouwer (Institut Jules Bordet, Brussels, Belgium) and SK-BR-3 cells were a gift from Dr. G. Daxenbichler (University of Innsbruck, Austria). CCL-64 and NRK cells were a gift from Dr. E. J. J. van Zoelen (Department of Cell Biology, University of Nijmegen, The Netherlands). Cells were cultured in $25 \mathrm{~cm}^{2}$ culture flasks from Greiner (Alphen a/d Rijn, The Netherlands) or in 96well low evaporation clusters from Costar (Badhoevedorp, The Netherlands).

\section{Methods}

\section{Cell culture}

Cells, routinely checked for mycoplasma contamination with a DNA-staining reaction using the bisbenzimidazole fluorochrome (Hoechst 33258), were maintained at $37^{\circ} \mathrm{C}$ in $5 \% \mathrm{CO}_{2}$ in air in their respective growth media. For the human breast cancer MCF7, T47-D, ZR/75.1 and ZR/HERc cells: RPMI- 1640 medium, containing phenol red and $21 \mathrm{mmol} / \mathrm{l}$ 4-(2-hydroxyethyl)-1-piperazineethanesulfonic acid (Hepes) and supplemented with $10 \%$ heatinactivated $\left(30 \mathrm{~min}\right.$ at $\left.56^{\circ} \mathrm{C}\right)$ bovine calf serum, $\mathrm{NaHCO}_{3}(10$ $\mathrm{mmol} / \mathrm{l})$, glutamine $(2 \mathrm{mmol} / \mathrm{l})$, penicillin $\left(100 \times 10^{3} \mathrm{U} / \mathrm{l}\right)$, streptomycin $(100 \mathrm{mg} / \mathrm{l})$ and gentamicin $(45 \mathrm{mg} / \mathrm{l})$. For MCF-7 cells this medium was supplemented with $10 \mathrm{mg} / \mathrm{l}$ porcine insulin, for $\mathrm{ZR}$ 75.1 and ZR/HERc cells with $1 \mathrm{nmol} / 17 \beta$-oestradiol, and for T47$D$ cells with $5 \mathrm{mg} / \mathrm{l}$ porcine insulin and $0.5 \mathrm{nmol} / 1$ 17 $\beta$-oestradiol. The human breast cancer EVSA-T, SK-BR-3 and MDA-MB-231 cells, the human colon cancer HT-29 cells, the mink long CCL-64 fibroblasts and normal rat kidney NRK fibroblasts were routinely cultured in DMEM/HAM F-12 medium containing phenol red and $14 \mathrm{mmol} / \mathrm{l} \mathrm{Hepes}$, with similar additions as described for the MCF7 cells. NRK cells were cultured in the latter medium in the absence of insulin and in case of EVSA-T cells $5 \%$ in stead of $10 \%$ heat-inactivated bovine calf serum was added.

Serum free medium used for experiments consisted of DMEM/ HAM F-12 medium without phenol red, but with $14 \mathrm{mmol} / \mathrm{l}$ Hepes and supplemented with $\mathrm{NaHCO}_{3}$, glutamine, penicillin, streptomycin and gentamicin as described for the MCF-7 cells. Bovine calf serum was replaced with $2 \mathrm{~g} / \mathrm{l}$ bovine serum albumin and $50 \mu \mathrm{g} / \mathrm{l}$ $\mathrm{Na}_{2} \mathrm{Se}_{2} \mathrm{O}_{3}$.

\section{MTT assay and cell harvest}

Cells were harvested from $25 \mathrm{~cm}^{2}$ culture flasks by trypsinization, resuspended in new medium, plated at different cell densities in 96-well culture plates and incubated at $37^{\circ} \mathrm{C}$ in $5 \% \mathrm{CO}_{2}$ in air for the time-period indicated in the legends of the figures. Medium was renewed every fourth day. Cells cultured for experimentation in serum-free medium were plated in growth medium to allow for attachment and flattening of the cells for 24 hours. Unless stated otherwise, the first and last of 12 rows of 8 wells of the plates contained medium only and 8 wells were used for each condition studied. To establish a relationship between the amount of formazan produced and cell number, cells from duplicate 96=well plates were either measured directly with the MTT assay or were 
harvested by trypsinization and counted with a haemocytometer. For cell counts, cultures were washed once with $200 \mu \mathrm{l}$ phosphatebuffered saline followed by the addition of $100 \mu \mathrm{l}$ trypsin-EDTA (trypsin, $250 \mathrm{mg} / \mathrm{l}$ and EDTA, $100 \mathrm{mg} / \mathrm{l}$ phosphate-buffered saline) to each aspirated well. Once cells were dissociated from the bottom of the wells, $100 \mu \mathrm{l}$ trypsin-inhibitor $(100 \mathrm{mg} / \mathrm{l}$ phosphate-buffered saline) was added to each well, and cells were subsequently removed from the wells with a $0.6 \times 25 \mathrm{~mm}$ needle attached to a $1 \mathrm{ml}$ syringe. After washing the wells with $100 \mu \mathrm{l}$ growth medium, cells from 8 or 16 replicate wells were pooled, pelleted at $100 \mathrm{~g}$ for 5 minutes, resuspended in $200 \mu \mathrm{l}$ growth medium, and counted with a haemocytometer. At regular intervals these cell counts were combined with the trypan blue exclusion assay to assess the number of viable cells. For this, $50 \mu \mathrm{l}$ cell suspension was added to $50 \mu \mathrm{l}$ trypan blue $(500 \mathrm{mg} / \mathrm{l}$ in phosphate-buffered saline) and the ratio of trypan blue excluding cells over blue stained cells was determined within 5 minutes with a light microscope.

Unless stated otherwise in the text, the MTT assay was performed basically as described (1) with some modifications. In brief, medium was aspirated from the wells and growth medium containing $650 \mathrm{mg} / 1 \mathrm{MTT}$ was added. This MTT-medium was freshly prepared from a filtered stock solution, kept in the dark at $4^{\circ} \mathrm{C}$, of $5 \mathrm{~g} / \mathrm{l}$ MTT in phosphate-buffered saline. Cells were incubated with MTT for 4 hours in the incubator $\left(37^{\circ} \mathrm{C} / 5 \% \mathrm{CO}_{2}\right)$. Subsequently, $100 \mu \mathrm{l}$ Uvasol quality dimethyl sulphoxide was added to each well after aspiration of the MTT-medium and the plates were shaken for 5 minutes on a microplate shaker. The absorbances at $540 \mathrm{~nm}$ were read immediately thereafter on an automatic microplate reader (Model 450, Bio-Rad Laboratories, Ltd., Watford, England).

\section{Absorbance spectra}

The spectra of formazan/dimethyl sulphoxide solutions were obtained from experiments in which formazan was produced by MCF-7 cells. Experimental conditions were as described in the legend to figure 1 . The spectra obtained with wavelengths between 400 and $680 \mathrm{~nm}$ were read with an UV-visible scanning spectrophotometer (UV-2101PC, Shimadzu Benelux, 's-Hertogenbosch, The Netherlands).

\section{Irradiation}

Cells were plated in 96-well culture plates as described in section MTT assay and cell harvest. One day after seeding, cultures were irradiated at room temperature with gamma rays using a Philips RT250 (250 kV, $15 \mathrm{~mA}$, Eindhoven, The Netherlands) with an irradiation dose of $0.5 \mathrm{~Gy} / \mathrm{min}$. All culture plates were removed from the incubator for the same time as those plates receiving the maximal dose of $8 \mathrm{~Gy}$.

\section{Statistics}

The unpaired Student's t-test, adjusted for unequal variances, was used to test for comparison of means. The Spearman rank correlation test was used for assessment of associations between groups. To test for differences between slopes of curves, the regression analysis (F-test) was used.

\section{Results}

\section{The formazan absorbance spectrum}

The spectrum of formazan, produced by MCF-7 cells, dissolved in dimethyl sulphoxide is susceptible to $\mathrm{pH}$ changes. Figure 1a shows that the position of the peak top shifts to a lower wavelength due to the addition of $\mathrm{HCl}$. This peak top shift is accompanied by a colour shift from purple-red to brown-red. Such spectrum shifts, which will result in lower absorbance values, can be overcome by adding a base such as $\mathrm{NaOH}$ to the solution (fig. 1b).

A similar peak top shift to a lower wavelength as observed after the addition of $\mathrm{HCl}$ was also found with a
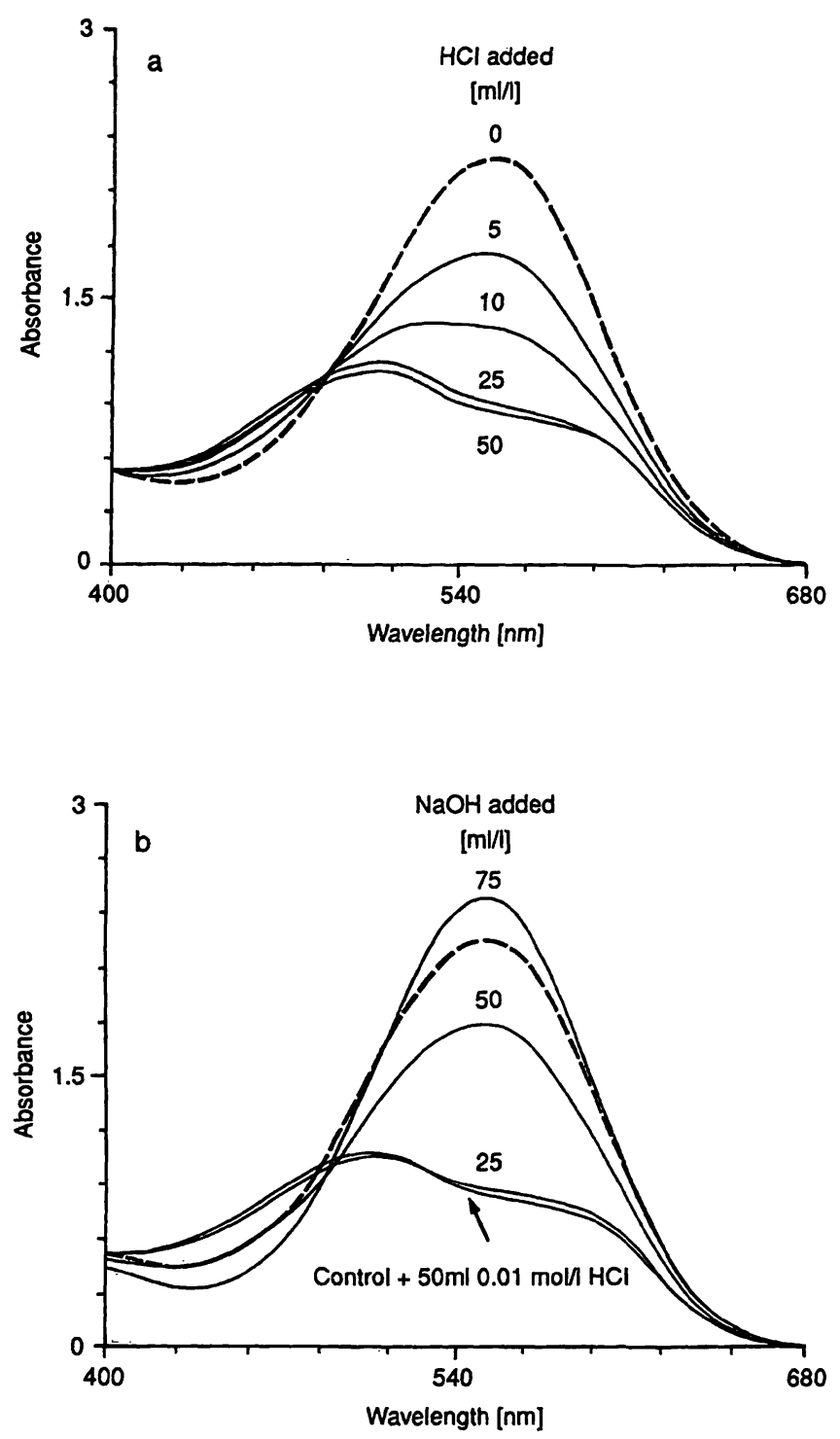

Fig. 1 Effects of acidification and alkalinization on the absorbance spectrum of a MTT-formazan/dimethyl sulphoxide solution. Logarithmically growing MCF-7 cells were incubated for 4 hours with MTT as described in Materials and Methods. At the end of the MTT-incubation period, the formazan crystals were dissolved in dimethyl sulphoxide (Uvasol quality). During the experiment the formazan/dimethyl sulphoxide solution was kept in the dark at room temperature. Increasing volumes of $0.01 \mathrm{~mol} / \mathrm{h} \mathrm{HCl}$ (a) followed by $0.01 \mathrm{~mol} / \mathrm{NaOH}$ (b) were added to the formazan/dimethyl sulphoxide solution and the blank (dimethyl sulphoxide only) as indicated in the figures. Note that after the addition of 50 $\mathrm{ml} / \mathrm{l} \mathrm{NaOH}(0.01 \mathrm{~mol} / \mathrm{l})$ to the solution already containing $50 \mathrm{ml} / \mathrm{l}$ $\mathrm{HCl}(0.01 \mathrm{~mol} / \mathrm{l})$ the absorbance value does not completely reach the absorbance value of the control (depicted by the dotted line) again because of a final $10 \%$ dilution of the formazan/dimethyl sulphoxide solution. 
formazan/dimethyl sulphoxide solution which contained a residue of MTT-medium. The presence of $50 \mathrm{ml} / \mathrm{l}$ MTT-medium in a formazan/dimethyl sulphoxide solution resulted in a peak top shift from $554 \mathrm{~nm}$ to $552 \mathrm{~nm}$. This was accompanied with a $22 \%$ (from 2.28 to 1.77 ) decrease in absorbance. On the other hand, the presence of $50 \mathrm{ml} / 1$ medium without MTT gave no shift of the peak top and resulted in only a $5 \%$ decrease in absorbance (from 2.28 to 2.17 ) due to dilution. To avoid a spectrum shift and a decrease in absorbance values it is therefore essential to remove the MTT-medium as completely as possible before the addition of dimethyl sulphoxide.

In additional experiments it was observed that the higher the cell density or the more exhausted (acidified) the culture medium, the larger the decrease in absorbance when medium was not renewed immediately prior to performing the MTT assay. Moreover, carrying out the assay in the absence of Hepes buffer in the MTT-culture medium resulted in a significant decrease (up to 60\%) in absorbances read at $540 \mathrm{~nm}$ as compared with Hepescontaining MTT-culture medium, while the absence or presence of serum or phenol red had no influence (data not shown). Therefore, as a standard, medium is renewed with Hepes-containing growth medium immediately prior to incubation with MTT $(650 \mathrm{mg} / \mathrm{l})$.

A spectrum shift may also occur as a result of the quality of dimethyl sulphoxide used. The colour of formazan, produced by T47-D cells after 2 days in culture, dissolved in "pro analysi" quality dimethyl sulphoxide was brown-red while the use of Uvasol dimethyl sulphoxide gave a purple-red solution. This spectrum shift was accompanied with a $30 \%$ lower absorbance at $540 \mathrm{~nm}$. The difference in spectrum optimum was probably due to the presence of some acidic substance(s) in "pro analysi" quality dimethyl sulphoxide, since the addition of 100 $\mathrm{ml} / 1 \mathrm{NaOH}(0.1 \mathrm{~mol} / \mathrm{l})$ nullified these differences (data not shown). Because it is difficult to aspirate MTT-medium completely without disturbing and aspirating some formazan crystals as well, and because of the observed differences between different batches of dimethyl sulphoxide, we alkalinized the formazan/dimethyl sulphoxide solutions. For this alkalinization we chose to add $10 \mathrm{ml} / 1 \mathrm{NH}_{3}$ from a $25 \%$ stock solution ( $\mathrm{pH} 11.4$ ) directly to the dimethyl sulphoxide solution instead of $\mathrm{NaOH}$ since it yielded identical results with significantly lower blank values for wells which had contained MTTmedium only (data not shown).

When culture plates containing formazan/dimethyl sulphoxide (Uvasol quality) solutions were exposed to air for 4 hours and 24 hours, decreases in absorbance of respectively $10 \%$ and $30 \%$ have been observed. Also, when formazan crystals were kept in an incubator $\left(37^{\circ} \mathrm{C}, 5 \% \mathrm{CO}_{2}\right.$ in air) for 5 days and subsequently dissolved in non-alkalinized Uvasol dimethyl sulphoxide immediately prior to measurement, the absorbance values had decreased $33 \%$ when compared to absorbance values obtained immediately after performing the MTT assay. When, however, the formazan/dimethyl sulphoxide solutions were alkalinized 'immediately prior to measurement, no decrease in absorbance was seen. Therefore, providing that the formazan/dimethyl sulphoxide solutions are alkalinized immediately prior to
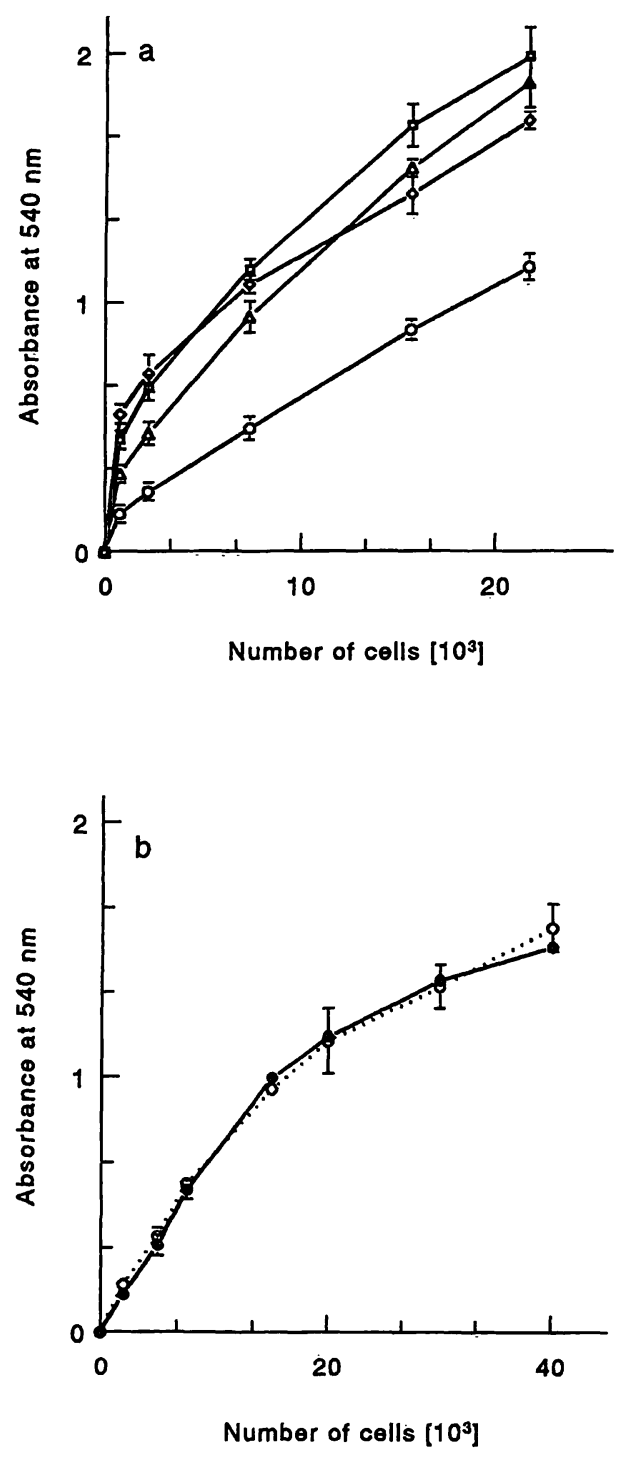

Fig. 2 Effect of different MTT-incubation times and two MTTconcentrations on the relationship between the absorbance of MTTformazan/dimethyl sulphoxide solutions and the number of cells. a) SK-BR-3 cells, seeded at a range of densities, were cultured for 4 days in growth medium. Subsequently, cultures were incubated for $6(-\diamond-), 4(-\square-), 2.5(-\Delta-)$, and $1\left(-0^{-}\right)$hour in the presence of MTT $(650 \mathrm{mg} / \mathrm{l})$, respectively $0,2,3.5$ and 5 hours after medium was renewed. During this time cultures grown in duplicate 96-wells culture plates were counted as described in Materials and Methods.

b) EVSA-T cells, seeded at a range of densities, were cultured for 1 day in growth medium. Subsequently growth medium was renewed and cultures were incubated for 2.5 hours in the presence of $650 \mathrm{mg} / \mathrm{l} \mathrm{MTT} \mathrm{(- \bullet -)} \mathrm{and} 1.3 \mathrm{~g} / 1$ MTT (----).

The data plotted are the mean absorbances \pm standard deviations for 8 wells at each cell number. 
measurement, it is possible to assay different conditions in one culture plate at different time-periods, simply by aspirating the MTT-medium and keeping the unsolved formazan crystals in the incubator for the time necessary for other cultures to be assayed. Furthermore, it is possible to freeze the formazan crystals in the culture plate, after aspirating the MTT-medium, for at least one week without affecting the absorbance values.

\section{Formazan production per cell}

\section{MTT-incubation time}

Depending on cell density, cell morphology and growth rate of different cell types, various incubation periods with MTT may be required. We have studied in a variety of cell types the effect of various MTT incubation periods, with a generally used MTT concentration of $650 \mathrm{mg} / 1(5,11)$ and have correlated the absorbance (formazan production) and the number of cells.

The example given in figure $2 \mathrm{a}$ for SK-BR-3 cells shows that the formazan production is time-dependent and that for reaching maximal absorbance values a 4-hour incubation period with this MTT-concentration of $650 \mathrm{mg} / 1$ is necessary. A prolonged incubation $(6 \mathrm{~h})$ results in a decreased measured absorbance if compared to a 4-hour incubation period, particularly at higher cell densities (fig. 2a: unpaired Student's t-test; $2 p<0.002$ for the two highest cell densities). Such an apparent reduced formazan production per cell likely resulted from leak- age of formazan crystals out of the cells, which had been perforated by the formazan crystals, into the medium. As a result, these free formazan crystals will be aspirated instead of being dissolved in dimethyl sulphoxide. The absence of a linear correlation between the number of cells and absorbance is not caused by limitations to the applicability of Beer's law, but is due to a diminished formazan production per cell at higher cell densities. This was concluded from the linear relationship which resulted between the absorbance and dilution factor after diluting the higher formazan concentrations of figure 2 in dimethyl sulphoxide. Doubling the MTT-concentration to $1.3 \mathrm{~g} / \mathrm{l}$ can not prevent this diminished formazan production per cell at higher cell densities. As illustrated in figure $2 \mathrm{~b}$ for EVSA-T cells, the use of $650 \mathrm{mg} / \mathrm{l} \mathrm{MTT}$ and $1.3 \mathrm{mg} / \mathrm{l} \mathrm{MTT}$ results in superimposable graphs.

In a manner similar to that used for SK-BR-3 cells, we determined the optimal MTT-incubation time for other logarithmically growing cell lines. The data collected in table 1, last column, show that occasionally a compromise has to be made to obtain the optimal MTT-incubation time for a particular cell line, because in some cases the higher cell densities need different incubation times than the lower cell densities. In table 1 a distinction has been made between the MTT-incubation time needed in the seemingly linear part of the calibration curve and the time needed in the bended part of the calibration curve. Except for the NRK and HT-29 cell lines, which require a 2.5 hours MTT-incubation period for either the linear or the bended part of the curve, 4 hours was chosen as

Tab. 1 Characteristics regarding cell size, morphology, doubling time and calibration curves of cells counted versus absorbance of 10 different cell lines in exponential growth.

\begin{tabular}{|c|c|c|c|c|c|c|c|}
\hline \multirow[t]{2}{*}{ Cell line } & \multirow{2}{*}{$\begin{array}{l}\text { Cell } \\
\text { size }^{\mathrm{a}}\end{array}$} & \multirow{2}{*}{$\begin{array}{l}\text { Morpho- } \\
\log ^{b}\end{array}$} & \multirow{2}{*}{$\begin{array}{l}\text { Doubling } \\
\text { time }^{c}\end{array}$} & \multicolumn{2}{|c|}{ Calibration curves } & \multicolumn{2}{|c|}{ MTT-incubation time (h) } \\
\hline & & & & Slope & $\begin{array}{l}\text { Linear } \\
\text { up to }(A)\end{array}$ & linear & bended \\
\hline SK-BR-3 & 3 & 2 & 3 & 0.277 & 0.5 & $4-6$ & 4 \\
\hline NRK & 1 & 2 & 1 & 0.242 & 0.7 & $2.5-4$ & 2.5 \\
\hline ZR/75.1 & 3 & 3 & 2 & 0.179 & 0.5 & $4-6$ & 4 \\
\hline ZR/HERc & 3 & 3 & 2 & 0.168 & 1.0 & $4-6$ & 4 \\
\hline MCF-7 & 2 & 2 & 2 & 0.111 & 1.0 & 4 & 4 \\
\hline HT-29 & 1 & 3 & 1 & 0.075 & 1.0 & 2.5 & $2.5-6$ \\
\hline T47-D & 3 & 3 & 3 & 0.063 & 1.0 & 4 & 4 \\
\hline EVSA-T & 2 & 2 & 2 & 0.061 & 1.0 & $2.5-6$ & $2.5-4$ \\
\hline MDA-MB-231 & 2 & 1 & 2 & 0.058 & 1.3 & $2.5-6$ & $2.5-4$ \\
\hline CCL-64 & $\overline{1}$ & 2 & $\ddot{1}$ & 0.053 & 1.3 & $2.5-6$ & $2.5-4$ \\
\hline
\end{tabular}

a The microscopically observed cell sizes after trypsinization have been divided into three categories: relatively small cells (1), cells of intermediate size (2), and relatively large cells (3).

b The morphologies of cells in culture have also been divided into three categories: cells growing separately from each other (1), cells growing in a monolayer with cell-cell contact such that it is possible to recognize the individual cells (2), and cells growing in clusters such that it is not possible to identify the individual cells in the cluster (3).

c The growth rates, i.e. doubling times of the cells in their respective growth media have been divided in cells growing relatively fast with doubling times less then 25 hours (1), cells growing relatively slowly with doubling times over 40 hours (3), and cells with doubling times in between (2).

The slopes of the calibration curves of cells counted versus absorbance have been determined from the seemingly linear part of the calibration curve. The absorbance values $(A)$ up to which the curves are linear are given in the column 'linear up to'. In the last column the time periods are given, needed to obtain an optimal production of formazan per cell. This column has been divided into two categories: the time needed in the approximately linear part of the curve and the time needed in the bended part of the curve. 
MTT-incubation period for all densities of the other cell lines tested.

\section{Metabolic activity}

Figure 3a shows calibration curves of the number of MCF-7 cells counted versus absorbance of MTTformazan produced by MCF-7 cells after up to 6 days in culture in growth medium. As can be expected of a metabolic viability assay, on a cell to cell basis the amount of formazan produced per cell in exponential
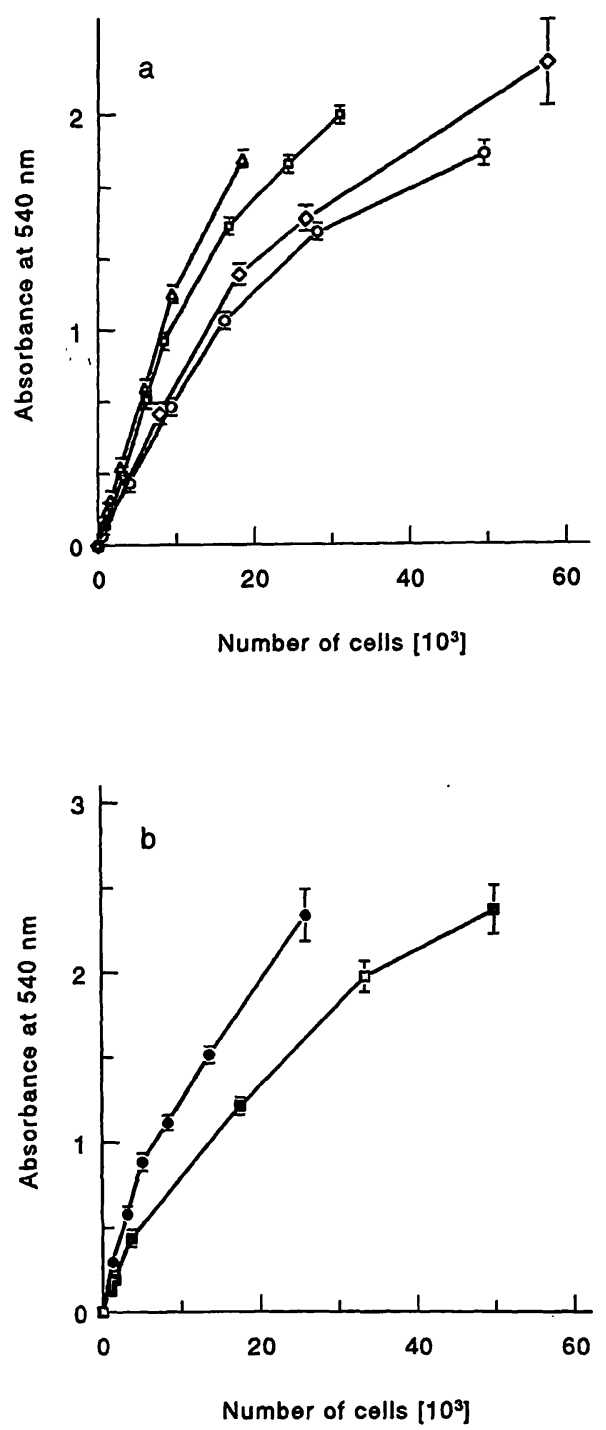

Fig. 3 Exponentially growing cells versus resting cells: effect on the relationship between the number of cells and absorbance of MTT-formazan produced by cells.

MCF-7 cells (a) and ZR/HERc cells (b) were seeded at a range of densities in growth medium. MCF-7 cells were cultured for 1 day $\left(-0^{-}\right), 3$ days $\left(-\Delta^{-}\right), 4$ days $\left(-\square^{-}\right)$and 6 days $\left(-\diamond_{-}\right)$in growth medium. For $Z R / H E R c$ cells, medium was exchanged for experimental medium supplemented with $1 \mathrm{nmol} / 117 \beta$-oestradiol and $1.7 \mu \mathrm{mol} / 1$ insulin (growth medium - - -, serum-free medium - - ) 18 hours after plating, whereafter cells were cultured for another 3 days. The MTT assay and cell counts were performed as described in Materials and Methods.

The data plotted are the mean absorbances \pm standard deviations for 8 wells at each cell number. growth, i. e. after 3 to 4 days for MCF- 7 cells cultured in growth medium, is higher then the amount of formazan produced by cells shortly after plating or after a prolonged time in culture (fig. $4 \mathrm{a}$ : F-test; $2 p<0.002$ for the slope of the curve at day 3 compared to the slope of the curve at day 6). Cells are still adapting to the environment shortly after plating ('day 1) and after a prolonged time in culture ( 6 days) cells are coming to rest due to contact inhibition and medium exhaustion.

When the assay is performed with cells which have been cultured for several days in medium deprived of factors essential for reaching exponential growth, the amount of produced formazan per quiescent cell will be significantly lower as compared with proliferating cells cultured in growth medium. Figure $3 \mathrm{~b}$ shows how this affects the calibration curves of cells counted versus $a b-$ sorbance of ZR/HERc cells cultured for 3 days in serumfree medium or growth medium, both media supplemented with $17 \beta$-oestradiol and insulin ( $F$-test; $2 p<0.002$ for the two slopes). After 3 days in culture the number of cells cultured in serum-free medium had not changed as compared with the number of seeded cells, while the number of cells cultured in growth medium had nearly doubled. The lower formazan production by cells cultured in serum-free medium was not due to a higher loss of formazan crystals in the medium as when compared with cells cultured in growth medium, but originated from a reduced metabolic activity.

In some instances, caution should be taken with respect to the interpretation of data obtained with the MTT assay. Two extreme examples of confounding results have been observed with the epidermal growth factor receptor positive ZR/HERc and SK-BR-3 cells (fig. 4). The oestrogen dependent ZR/HERc cells significantly increase in size after epidermal growth factor treatment in serum-free medium supplemented with $17 \beta$-oestradiol $(1 \mathrm{nmol} / \mathrm{l})$. Additionally the culture loses its cluster wise morphology. The formazan production of $\mathrm{ZR} /$ HERc cultures incubated with $5 \mu \mathrm{g} / \mathrm{l}$ epidermal growth factor after 2 and 4 days was respectively 1.5 and 2.1 times higher when compared to the control cultures lacking epidermal growth factor (fig. 4; left panel, closed bars). This was not accompanied by a higher relative cell number after 2 days and only a 1.4 times higher cell number after 4 days as compared with epidermal growth factor lacking cultures at day 2 and 4 respectively (fig. 4; left panel, open bars). The absolute cell number in the absence of epidermal growth factor had decreased with $25 \%$ after 4 days. The results obtained with the MTT assay merely reflected an increased metabolic activity of cells treated with epidermal growth factor. Another example of a discrepancy between the MTT assay and cell count has been found with SK-BR- 


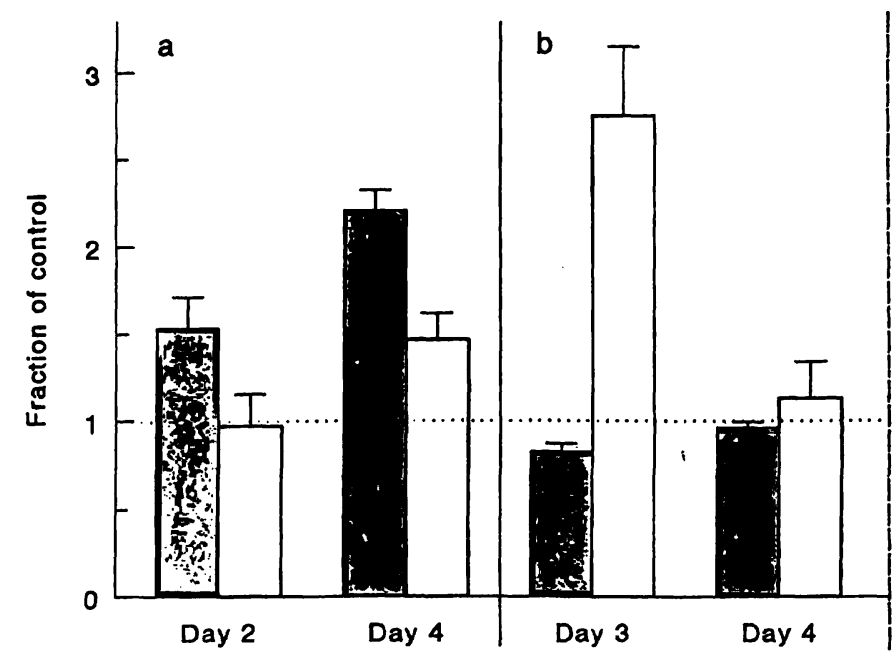

Fig. 4 Effect of metabolic activity on the relationship between number of cells counted and absorbance of MTT-formazan produced.

ZR/HERc (a) and SK-BR-3 (b) cells were seeded in 4 different densities in growth medium. After 24 hours growth medium was exchanged for experimental serum-free medium; for $Z R / H E R c$ cells supplemented with $1 \mathrm{nmol} / 17 \beta$-oestradiol, in the absence or presence of epidermal growth factor (1 and $5 \mu \mathrm{g} / \mathrm{l}$ for SK-BR-3 and ZR/HERc cells, respectively) whereafter cells were cultured for up to 4 days. The MTT assay (closed bars) and cell counts (open bars) were performed as described in Materials and Methods. Results are expressed as 'fraction of control' i. e. fraction of absorbance values obtained at the indicated time-points for the control cultures lacking epidermal growth factor (dotted line). The data plotted are the means \pm standard deviations from cultures seeded in 4 different densities. Each cell density was incubated in 8-fold. Absolute absorbance values were in all cases between 0.15 and 1.2.

3 cells incubated with $1 \mu \mathrm{g} / 1$ epidermal growth factor (fig. 4; right panel). Microscopical viewing of cell cultures showed that, after a 3 day culture period in serumfree medium, the cell membranes of the epidermal growth factor treated cultures were less clearly visible when compared with the cell membranes of the control cultures. At this time, the same amount of cells plated produced $18 \%$ less formazan after epidermal growth factor incubation if compared with untreated controls (fig. 4; right panel, day 3 , closed bars). The number of cells present in the epidermal growth factor treated cultures nevertheless was almost 3 times higher then the number of trypan blue excluding cells counted in the control cultures (fig. 4; right panel, day 3, open bars), which however was still less then the amount plated initially. The reason for this discrepancy became more clear after another day of culture. The cells were dying, as cell counts confirmed (fig. 4; right panel, day 4, open bars). The results of the MTT viability testing assay were one day ahead of the cell count results. The same experiments performed with cells in serum-containing medium, which enables the control cultures to maintain their metabolic activity, showed that the number of counted cells correlated with the results of the MTT assay (data not shown).

\section{Calibration curves}

Even when calibration curves of the number of cells counted versus absorbance values obtained with the MTT assay are derived from cells in exponential growth, the slope of the calibration curves are different for different cell lines (fig. 5). This suggests different capacities of cells to produce formazan, possibly as a result of different morphology and growth characteristics of these various cell lines. In table 1 the characteristics regarding cell size, morphology, and growth rate of 10 different cell lines in exponential growth are given. Overall there appears to exist a negative correlation between the slope of the linear area of the calibration curve and the absorbance value up to which there exists a linear relationship (Spearman Rs $=-0.76 ; 2 p<0.02$ ). The steeper the slope, i.e. the higher the amount of formazan produced per cell, the lower the absorbance value up to which the relationship between cells counted and absorbance is linear. As shown in table 1, there is no clear relationship between cell size and slope. Growth rate and morphology of cells in culture also seem to play a role. For example, cells growing relatively fast appear to produce more formazan per cell than cells growing more slowly (compare the approximately similar sized, in clusters growing, ZR/75.1 cells with a doubling time of about 36 hours with the T47-D cells, which have a doubling time of over 50 hours, with slopes of the calibration curves of 0.179 and 0.063 , respectively). On the other hand, cells growing in a cluster appear to produce less formazan per cell. This is illustrated by comparing two cell lines with comparable doubling times, i. e. in cluster

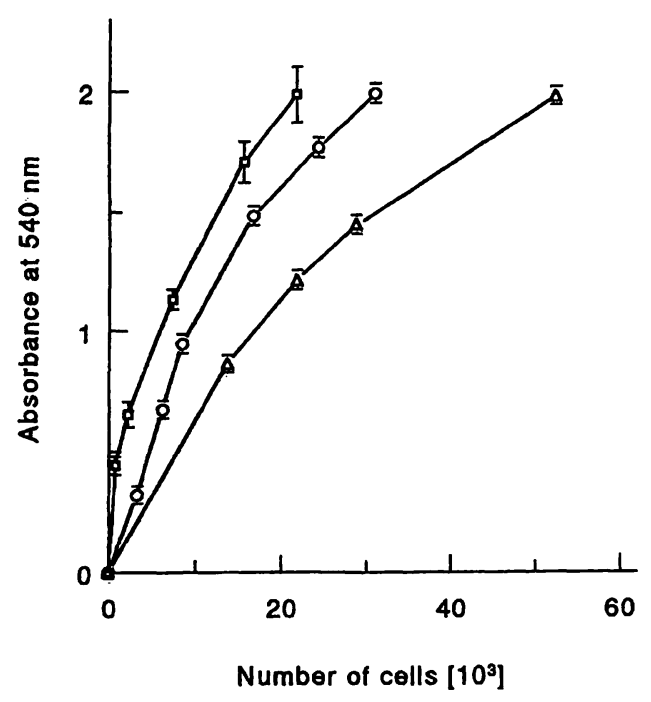

Fig. 5 Calibration curves of number of cells counted versus absorbance values obtained with the MTT assay.

SK-BR-3 (- - -), MCF-7 (-O-) and T47-D (- - -) cells, seeded at a range of densities, were cultured for 4 days in growth medium in order to obtain exponential growth. The MTT assay and cell counts were performed as described in Materials and Methods.

The data plotted are the mean absorbances \pm standard deviations for 8 wells at each cell number. 
growing T47-D cells and the approximately similar sized separately growing SK-BR-3 cells, with slopes of 0.063 and 0.277 , respectively (tab. 1).

\section{Practical use of MTT assay}

\section{Determination of doubling times}

Given that the absorbance values are within the approximate linear part of the assay (see tab. 1), and are obtained with formazan produced by cells in exponential growth, cell doubling times can be calculated from the linear equation obtained after semi-logarithmical transformation of the data of time versus absorbance. From the example shown in figure 6, the calculated doubling times (with the $95 \%$ confidence interval) for MCF-7, EVSA-T and CCL-64 cells are 36.9 (35.7-38.2), 28.4 (26.6-30.4) and $22.2(21.5-22.9)$ hours respectively. These doubling times compare with those obtained from simultaneously performed cell counts, i. e. 37,26 and 20 hours for MCF-7, EVSA-T and CCL-64, respectively.

\section{Extrapolation of growth curves}

A very useful application of the MTT assay may involve the construction of survival curves following irradiation of the cells. To produce reliable survival curves, it is desirable to use a large range of values. The linearity of the MTT assay is limited and variable for various cell lines (tab. 1). With the use of a calibration curve of cells counted versus absorbance made with exponentially

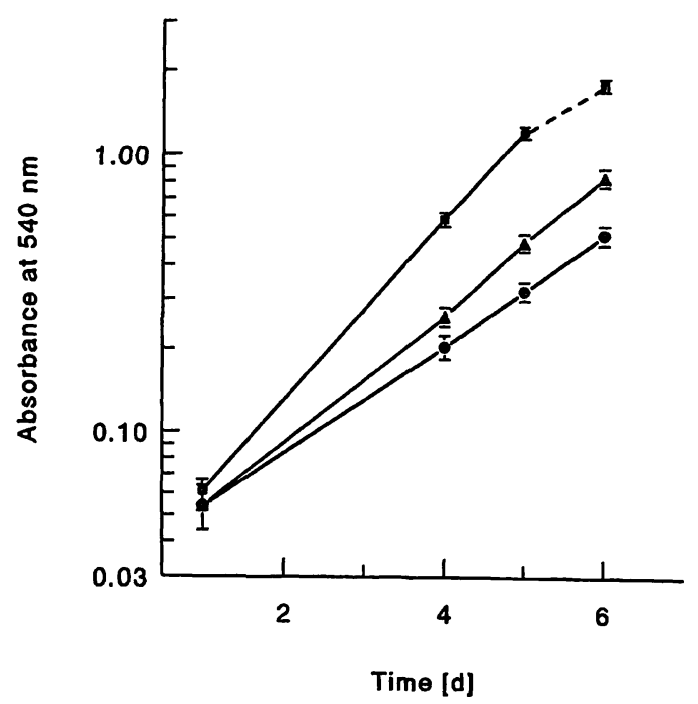

Fig. 6 Determination of doubling times.

1000 CCL-64 cells (-口-), 2500 EVSA-T cells (- - -) and 2500 MCF-7 cells (-0-) were seeded and cultured for up to 6 days in their respective growth media, with a medium renewal at day 3 . The MTT assay was performed as described in Materials and Methods.

The absorbance data of formazan produced by these cells in exponential growth have been logarithmically transformed to allow calculation of cell doubling times from the obtained linear equation. growing cells, the range can be significantly extended. An example of survival curves made for EVSA-T cells after up to $8 \mathrm{~Gy}$ irradiation is illustrated in figure 7. Ab-


Fig. 7 Construction of a true survival curve by extrapolation of growth curves.

a) Eighteen hours after seeding 2500 EVSA-T cells in growth medium, cultures were irradiated with 0 Gy $(-0-), 2$ Gy $(-\square-)$, 4 Gy $\left(-\Delta^{-}\right), 6 \mathrm{~Gy}\left(-\diamond^{-}\right)$or $8 \mathrm{~Gy}(-\nabla-)$ and allowed to grow, i. e. obtain exponential growth, for up to 16 days with a medium renewal every third or fourth day. The MTT assay and irradiation procedure were performed at the indicated time points as described in Materials and Methods. The data plotted are the mean absorbances for 8 wells at each time-point. Standard deviations were in all cases less than $10 \%$.

b) A calibration curve of absorbance against cell number made of these EVSA-T cells in exponential growth, i. e. after 4 days in culture, was used to translate absorbance data of formazan produced by these cells into the actual number of cells present. Cell numbers were logarithmically transformed to obtain a linear equation of the data of time versus number of cells. After the irradiated cultures had reached exponential growth, curves were extrapolated with the slope of the growth curve of the non-irradiated control culture.

c) Data obtained either by actual measurement or after extrapolation of growth curves were used to construct the apparent survival curves after $6(-\Delta-), 8\left(-\square^{-}\right)$and $11(-0-)$ days in culture and the true survival curve after 16 days $\left(-0^{-}\right)$in culture. 
sorbance values of irradiated EVSA-T cells after up to 16 days in culture have been converted to the actual number of cells present. Figure 7a shows that it may take as long as 16 days before cells irradiated with $8 \mathrm{~Gy}$ reach true exponential growth, while cells exposed to lower dosages have reached confluency long before. Semi-logarithmic plotting of the data of time versus number of cells enables extrapolation as based on the slope (= true growth rate) of the control cultures (fig. $7 b$ ). It is illustrated in figure $7 \mathrm{c}$ that accurate survival results are obtained only after all cultures have reached exponential growth, i. e. 16 days or longer after irradiation. The other examples given (after 6, 8 and 11 days of culture) do not represent true survival curves as defined by Hall (23).

\section{Performance of the MTT assay}

The between-assay performance of the MTT assay is listed in table 2 , showing the mean absorbances \pm standard deviations obtained from 10 independent consecutive experiments, performed over a 2-month period, in which MCF-7 cells were cultured for 4 days in 4 different media. The coefficients of variation for the 10 experiments with 4 different culture conditions ranged from $13-22 \%$.

\section{Discussion}

One of the major advantages of the use of the MTT assay is the ability to measure in a relatively short time, even within a cell doubling period, differences in metabolic activity. We have shown that, with the described precautions taken regarding the MTT incubation medium, the MTT incubation time and the formazan/dimethyl sulphoxide spectrum, the coefficients of variation for 10 independent consecutive experiments for 4 different culture conditions ranged from $13-22 \%$. This

Tab. 2 The between-assay performance of the MTT assay. The mean absorbances \pm standard deviations (S.D.) and coefficients of variation (CV) for the 10 experiments are derived from 10 independent consecutive experiments performed over a 2-months period. For this, $5000 \mathrm{MCF}-7$ cells were seeded in growth medium. After 24 hours medium was exchanged for experimental serumfree medium or growth medium in the absence or presence of $1 \mathrm{nmol} / 117 \beta$-oestradiol, whereafter cells were cultured for another 3 days. The MTT assay was performed as described in Materials and Methods.

\begin{tabular}{lll}
\hline Culture condition & $\begin{array}{l}\text { Mean } \pm \text { S.D. } \\
\left(A_{540}\right)\end{array}$ & $\begin{array}{l}\text { CV } \\
(\%)\end{array}$ \\
\hline Serum-free medium & $0.215 \pm 0.046$ & 21 \\
Serum-free medium ' oestradiol & $0.445 \pm 0.097$ & 22 \\
Growth medium & $0.801 \pm 0.105$ & 13 \\
Growth medium + oestradiol & $0.956 \pm 0.184$ & 19 \\
\hline
\end{tabular}

is considered acceptably low, because included in this variation are also the within-assay variation (less than $10 \%$ for all experiments described in the present paper), and the variations in cell count at time of seeding for the 10 different experiments.

Spectrum shifts of formazan/dimethyl sulphoxide solutions, accompanied by a decrease in absorbance values, have been described previously $(1,12)$ and were attributed to a number of reasons amongst which are the cell density of cultures assayed (12), the presence of residual serum $(15)$, or culture medium $(1,12)$ left after aspiration before solving the formazan crystals in dimethyl sulphoxide.

In this study we have shown that the presence of acidic residues in the formazan/dimethyl sulphoxide solution causes a shift of the peak top of the spectrum resulting in decreased absorbance values (fig. 1). Control of $\mathrm{pH}$ during incubation of cells with MTT and after dissolving the formazan crystals in dimethyl sulphoxide appears to be extremely important. Control of the $\mathrm{pH}$ during incubation with MTT can be achieved by renewing the medium with Hepes-containing culture medium immediately prior to incubation with MTT. Medium renewal prior to incubation with MTT has a number of advantages: no (lack of) substances which may interfere in the process of converting MTT to formazan caused by e.g. differential medium conditioning of different cultures (2), NADH, NADPH and/or glucose depletion in the culture medium (4), the presence of agents like suramin (16) or other test agents which may affect the reductive capacity of cells as a result of enzymatic regulation (2). However, the formazan/dimethyl sulphoxide spectrum may be influenced by factors different from those which play a role during the MTT-incubation period. For.example, we observed differences in the absorbance spectrum of formazan/dimethyl sulphoxide solutions due to the use of different qualities of dimethyl sulphoxide. Furthermore we observed that prolonged exposure of formazan crystals to air, in the absence or presence of dimethyl sulphoxide, resulted in a shift of the formazan/ dimethyl sulphoxide spectrum. An advantage is that spectrum shifts are accompanied with colour shifts from purple red to brown red, which are easily detectable after the crystals have been dissolved in dimethyl sulphoxide. If such a colour shift is observed, it is imperative to alkalinize the formazan/dimethyl sulphoxide solution. This should preferentially be performed with a base which gives no increase in background absorbances, otherwise the reliability and reproducibility will be compromised by the resulting low signal/noise ratios. Therefore, we add $10 \mathrm{ml} / 1 \mathrm{NH}_{3}$ from a $25 \%$ stock solution (pH 11.4) to the formazan/dimethyl sulphoxide solution because this results in a maximum peak height at 540 
$\mathrm{nm}$ without significantly increasing the background values.

Various reports (e.g. 1, 4, 5, 12, 14) have shown

1) the absence of a linear correlation between cell number and absorbance,

2) the differences in amount of formazan produced per cell, and

3) the necessity for establishing optimal assay conditions (MTT-concentration and incubation time) for each individual cell line.

We have shown that the absence of a linear correlation between cell number and absorbance is caused by a diminished formazan production per cell at higher cell densities. A number of reasons (figs. 3 and 4) for this diminished formazan production per cell have been given. Proliferating cells for example, produce more formazan than cells deprived of factors essential for proliferation. This phenomenon is one of the major advantages of the use of the MTT assay: the ability to measure in a relatively short time differences in metabolic activity.

Providing that the absorbance values are within the (seemingly) linear part of the curve of cells counted versus absorbance, relative responses between two cultures can be determined by comparing their "fraction of the absorbance values of the control cultures" or by comparing their proliferation index (24). Furthermore, the MTT assay can be used as an alternative to the clonogenic assay (4). Advantages of the MTT assay are that responses of cell lines which do not grow as colonies can be measured, and moreover it is less time consuming and less prone to personal interpretations because of the automated read-out. In order to obtain treatment results which are comparable with the clonogenic assay, calibration curves of absorbance against cell number need to be used. As we have shown in figure 7 for irradiated cultures, accurate surviving fractions or $\mathrm{IC}_{50}$-values for different agents can be calculated only when cells are in exponential growth. Therefore, the calibration curves should be made with cells in exponential growth. With these calibration curves it is possible

1) to overcome the absence of a linear relationship between cell number and the higher absorbance values,

2) to extend the range of values, and

3) to correct for the differences in formazan production between cell lines.

If the MTT assay is used in order to obtain results comparable with for example cell count experiments, one has to be aware that with cell counting no distinction is made between metabolically active and inactive cells. As we have demonstrated in figure 4, this may give rise to an over- or under-estimation of MTT results if compared to cell count results. Morphological changes may precede such confounding results between assays based on different principles. In table 1 and figure 5 we have shown that cells growing in a cluster produce less formazan per cell if compared to cells growing in a monolayer. This reduced production of formazan by cells growing in a cluster may originate from the lack of available MTT in the center of the cluster. On the other hand it is possible that cells in the center of a cluster are less viable due to local confluency, in which case the MTT assay reflects the genuine condition of the culture. One has to take this property of the MTT assay into account. If morphological changes are observed, we propose to use the MTT assay only as a quick screening method and to use other assay(s) to verify the true impact of the results.

In conclusion, we have shown that the MTT assay can be used as a reliable assay, provided that necessary precautions as described above are taken, to measure metabolic activity of cell cultures in vitro for the assessment of growth characteristics, $\mathrm{IC}_{50}$-values and cell survival.

\section{Acknowledgements}

We thank $E l s M . J . J$. Berns for her helpful suggestions with the manuscript and Maxime P. Look for performing statistical analysis.

\section{References}

1. Carmichael J, De Graff WG, Gadzar AF, Minna JD, Mitchell JB. Evaluation of tetrazolium-based semi-automated colorimetric assay: assessment of chemosensitivity testing. Cancer Res 1987; 46:936-41.

2. Jabbar SA, Twentyman PR, Watson JV. The MTT assay underestimates the growth inhibitory effects of interferons. Br J Cancer 1989; 60:523-8.

3. Mosmann T. Rapid colorimetric assay for cellular growth and survival: application to proliferation and cytotoxity assays. J Immunol Methods 1983; 65:55-63.

4. Price $P$, McMillan TJ. Use of the tetrazolium assay in measuring the response of human tumor cells to ionizing radiation. Cancer Res 1990; 50:1392-6.

5. Romijn JC, Verkoelen CF, Schroeder FH. Application of the MTT assay to human prostate cancer cell 'lines in vitro: establishment of test conditions and assessment of hormone-stimulated growth and drug-induced cytostatic and cytotoxic effects. Prostate 1988; 12:99-110.

6. Loveland BE, Johns TG, Mackay IR, Vaillant F, Wang ZX, Hertzog PJ. Validation of the MTT dye assay for enumeration 
of cells in proliferative and antiproliferative assays. Biochem Int 1992; 27:501-10.

7. Miyazaki N, Ohkura $H$, Kajimura N, Okazaki N. A rapid anticancer screening assay by $\left[{ }^{14} \mathrm{C}\right.$ [thymidine uptake in cultured human cancer cells. Eur J Cancer 1992; 28:1419-22.

8. Garewal HS, Ahmann FR, Schifman RB, Celniker A. ATP assay, ability to distinguish cytostatic from cytocidal anticancer drug effects. J Natl Cancer Inst 1986; 77:1039-45.

9. Janjic $D$, Wollheim CB. Islet cell metabolism is reflected by the MTT (tetrazolium) colorimetric assay. Diabetologia 1992; 25:482-5.

10. Yamashoji S, Nishimoto $F$, Usuda $M$, Kubota $H$, Isshiki $K$. Application of the chemiluminescent assay to cytotoxicity test: detection of menadione-catalyzed $\mathrm{H}_{2} \mathrm{O}_{2}$ production by viable cells. Anal Biochem 1992; 207:255-60.

11. Heo DS, Park JG, Hata K, Day R, Herberman RB, Whiteside TL. Evaluation of tetrazolium-based semiautomatic colorimetric assay for measurement of human antitumor cytotoxity. Cancer Res 1990; 50:3681-90.

12. Plumb JA, Milroy R, Kaye SB. Effects of the pH dependence of 3-(4,5-dimethylthiazol-2-yl)-2,5-diphenyl-tetrazolium bromide-formazan absorption on chemosensitivity determined by a novel tetrazolium-based assay. Cancer Res 1989; 49:44359-40.

13. Schweitzer CM, Loosdrecht v/d AA, Jonkhoff AR, Ossenkoppele GJ. Spectrophotometric determination of clonogenic capacity of leukemic cells in a semisolid microtiter culture system. Exp Hematol 1993; 21:573-8.

14. Vistica DT, Skehan P, Scudiero DA, Monks A, Pittmann A, Boyd MR. A critical examination of selected parameters affecting formazan production. Cancer Res 1991; 51:2515-20.

15. Nargi FE, Yang TJ. Optimization of the L-M cell bioassay for quantitating tumor necrosis factor alpha in serum and plasma. J Immunol Methods 1993; 159:81-91.

16. Foekens JA, Sieuwerts AM, Stuurman-Smeets EMJ, Dorssers LCJ, Berns EMJJ, Klijn JGM. Pleiotropic actions of suramin on the proliferation of human breast-cancer cells in vitro. Int J Cancer 1992; 51:439-44.
17. Campling BG, Pym J, Galbraith PR, Cole SPC. Use of the MTT assay for rapid determination of chemosensitivity of human leukemic blast cells. Leukemia Res 1988; 12:823-31.

18. Jordan JP, Handt CM, Makowitz RS, Black P. Test for chemotherapeutic sensitivity of cerebral gliomas: use of colorimetric MTT assay. J Neurooncol 1992; 114:19-35.

19. Thom SM, Herobin RW, Seidler E, Barer MR. Factors affecting the selection and use of tetrazolium salts as cytochemical indicators of mircrobial viability and activity. $\mathrm{J}$ Appl Bacteriol 1993; 74:433-43.

20. Furukawa T, Kubota T, Watanabe M, Kase S, Takahara T, Yamaguchi $\mathrm{H}$, et al. Chemosensitivity testing of clinical gastrointestinal cancers using histoculture and the MTT-end point. Anticancer Res 1992; 12:1377-82.

21. Haber M, Madafiglio J, Norris MD. Methotrexate cytotoxicity determination using the MTT assay following enzymatic depletion of thymidine and hypoxanthine. J Cancer Res Clin Oncol 1993; 119:315-7.

22. Dorssers LCJ, Agthoven van T, Sieuwerts AM. Genetic mechanisms involved in progression to hormone independence of human breast cancer. In: Berns EMJJ, Romijn JC, Schröder $\mathrm{FH}$, editors. Mechanisms of progression to hormone independent growth of breast and prostatic cancer. Carnforth (UK): Parthenon, 1991:169-82.

23. Hall EJ. Cell-survival curves. In: Radiobiology for the radiologist. Philadelphia: Harper \& Row, 1978:29-62.

24. Roozendaal van CEP, Ooijen van B, Klijn JGM, Claassen C, Eggermont AMM, Henzen-Logmans SC, Foekens JA. Stromal influences on breast cancer cell growth. Br J Cancer 1992; 65:77-81.

A. M. Sieuwerts

Division of Endocrine Oncology

Department of Medical Oncology

Dr. Daniel den Hoed Cancer Center

PO Box 5201

NL-3008 AE, Rotterdam

The Netherlands 


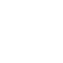

